\title{
THE FREQUENCY OF MISMATCH REPAIR DEFICIENCY IN COLORECTAL CARCINOMA DETERMINED BY IMMUNOHISTOCHEMISTRY
}

\author{
Maria Naseem, Muhammad Asif, Hafeez Ud Din, Muhammad Tahir Khadim, Ahmed Ahson Khan, Shahid Jamal*, Iman Shoaib \\ Armed Forces Institute of Pathology/National University of Medical Sciences (NUMS) Rawalpindi Pakistan, *Watim Medical College, Rawalpindi Pakistan
}

\section{ABSTRACT}

Objective: To determine the frequency of mismatch repair deficiency in colorectal carcinoma determined by immunohistochemistry.

Study Design: Cross-sectional study.

Place and Duration of Study: Department of Histopathology, Armed Forces Institute of Pathology, Rawalpindi, from Aug 2018 to Jan 2019.

Methodology: A total of 101 patients of adenocarcinoma of colorectum who underwent surgical resections and their characteristic and clinical data were recorded. Immunohistochemical stains were performed using antibodies MLH1, MSH2, PMS2 and MSH6. Results were interpreted and mismatch repair deficiency status of all patients was determined. Patients with loss of expression for MLH1, MSH2, PMS2 and MSH6 antibodies were observed and noted.

Results: In this study, out of 101 patients with CRC, 71 (70.3\%) were male and $30(29.7 \%)$ female. The mean age was (54 years \pm 15.9 ). Amongst the 101 cases loss of immunohistochemical staining for MMR proteins was noted in 19 patients $(18.8 \%)$. The combined loss of all four antibodies was seen in one case, loss of MLH1 and PMS2 in 7, MSH2 and MSH6 in 5 and MLH1 only in 6 patients. However, no mismatch repair deficiency was detected in remaining 82 cases. According to statistical analysis no significant association between mismatch repair deficiency and variables was found.

Conclusion: The frequency of mismatch repair deficiency in colorectal carcinoma patients was found to be $18.8 \%$ in our population.

Keywords: CpG island methylation phenotype, Colorectum, Immunohistochemistry, Mismatch repair deficiency, Microsatellite stable, Microsatellite instable.

This is an Open Access article distributed under the terms of the Creative Commons Attribution License (https://creativecommons.org/licenses/by-nc/4.0/), which permits unrestricted use, distribution, and reproduction in any medium, provided the original work is properly cited.

\section{INTRODUCTION}

Colorectal carcinoma (CRC) is one of the most common malignancies in the developed countries including; North America, Russia and Australia. Each year around 500,000 new cases of CRC are diagnosed worldwide ${ }^{1}$.

Several factors have been considered responsible for the significantly increased incidence such as; smoking, poor nutrition and obesity. However, the burden of colorectal cancer is preventable to a larger extent by early detection, spreading awareness related to healthy dietary patterns, tobacco control, reducing the utilization of red and processed meat encouraging physical activity and maintaining a healthy body weight ${ }^{2}$.

Colorectal cancer being insidious in onset follow a sequence of genetic alterations that includes; activation of proto-oncogene such as loss of APC gene on 5q21 region of chromosome, and inactivation of tumor suppressor genes such as loss of $p 53$ gene on $17 p 13$ and loss of heterozygosity on chromosome 18 at long arm i.e. $18 \mathrm{q} \mathrm{LOH}^{3}$. According to the molecular analyses, there

Correspondence: Dr Maria Naseem, Department of Histopathology, Armed Forces Institute of Pathology, Rawalpindi Pakistan

Received: 10 Mar 2020; revised received: 04 Jun 2020; accepted: 08 Jun 2020 are two principles that support that genetic alterations are responsible for pathogenesis in the CRC i.e. Familial adenomatous polyposis is the result in the Adenomatous polyposis coli (APC) gene mutation and the factors that are associated with CRC have proved to have carcinogenic effects ${ }^{4}$. In general, the alterations in length observed within the simple repeated sequences are known as microsatellite. However, the stability of microsatellite is dependent on DNA Mismatch repair (MMR) system. MMR enables recognition and repairing of the damages occurring during DNA replication and recombination such as deletions, inaccurate insertions and mis-assimilation of the DNA bases. Microsatellite instability (MSI) is a genetic hypermutable state as a result from defect in the DNA mismatch repair (MMR). The cells with defective MMR fail to remove the errors occurring during DNA replication and hence errors accumulate leading to mutation. However, MSI operates as second major pathway after chromosomal instability or microsatellite stable pathway in the carcinogenesis of $\mathrm{CRC}^{5}$. Three groups of tumors are defined on the basis of mutation of MSI markers; MLH1, MSH2, PMS2 and $\mathrm{MSH}^{6}$. The tumors showing no instability are called microsatellite stable (MSS); tumors possessing $<30 \%$ of the mutated microsatellite marker 
panel are called MSI-Low, and tumors consisting $>30 \%$ of the mutated microsatellite marker panel are called MSI-High. Another type of MSI called "Elevated microsatellite alterations at selected tetranucleotide repeat" (EMAST) have been reported, these repeats have been found to be associated with p53 mutations ${ }^{6}$.

Colorectal cancers with mismatch repair deficiency is characterized with distinguished features; involvement of proximal colon, tumor infiltrating lymphocytes (activated and cytotoxic), mucinous and signet ring cell component and poor differentiation. These tumors have a favorable prognosis compared to CRC without mismatch repair deficiency and show different response to chemotherapy ${ }^{7}$. In general, evaluation of mismatch repair deficiency status in CRC is considered for Lynch syndrome (hereditary nonpolyposis colorectal cancer, or HNPCC), that is a hereditary disorder caused by inactivation of the germline mutations in genes coding mismatch repair factors. Patients with Lynch syndrome have unique and inherited features including tumor development at early ages (usually between 20-30 years of age), occurrence of multiple tumors in the body (including colon, rectum, stomach, small intestine, urinary tract, ovary, endometrium and other sites), low-stage disease at the time of diagnosis and less metastatic potential. The analyses of mismatch repair deficiency and its related molecular alterations in the clinical settings are currently increasing, and mismatch repair deficiency status is considered a useful marker for screening the patients with Lynch syndrome and as a prognostic factor in the field of chemotherapeutic interventions ${ }^{8}$. There are four genes that are mutated in the Lynch syndrome including MLH1, MSH2, PMS2, and MSH6. On the basis of mismatch repair (MMR) capacity, the CRC are classified into MMR-proficient (with intact MMR proteins) and MMR-deficient tumors (with loss of function of MMR pathway) ${ }^{9}$.

The molecular MSI testing is considered as "gold standard" for assessing the tumor DNA mismatch repair system competency. However, this test is laborintensive and time consuming involving the DNA extraction both from tumor and normal tissue, polymerase chain reaction (PCR) amplification of DNA, running the amplified products of tumor and normal tissue followed by comparing and scoring the difference which makes this test clinically troublesome as surgeon would preoperatively like to know the likelihood of HNPCC to decide the extent of surgery. In contrast, monoclonal antibodies are commercially available to the protein products of hMLH1, hMSH2, hPMS2 and hMSH6. In comparison to molecular MSI testing, IHC detection of MMR proteins is less labor intensive and less time consuming and provides an alternative method for detection of MMR deficiency ${ }^{10}$.

There are different therapeutic responses in MSIH CRCs depending on type of adjuvant chemotherapy. Although, use of mismatch repair deficiency status have been controversial for its response towards adjuvant chemotherapy, but tumor with MSI-high, is diagnosed with either Lynch syndrome or Methylated. In case of IHC done and the unexpressed protein is MSH2, PMS2 or MSH6, germline testing is required for deleterious mutation in mismatch repair to diagnose it to be Lynch syndrome. If the unexpressed protein is MLH1, possibility could be of CIMP tumor with hypermethylation of MLH1 promoter, or Lynch syndrome.

In this study, we determined the frequency of mismatch repair deficiency status by immunohistochemistry in 101 patients who went through surgical resection for CRC. As a part of this study, we evaluated the possible association with age, gender, location of tumor and smoking as variables. However, the patient's family history of CRC, young age at the time of diagnosis proximal tumor location was considered the independent predictors of mismatch repair deficiency status.

\section{METHODOLOGY}

This was a cross-sectional study, conducted at department of Histopathology, Armed Forces Institute of Pathology (AFIP) Rawalpindi, Pakistan from August 2018 to January 2019. The sample size was determined using WHO calculator and based on the given prevalence of $34 \%$ inmismatch repair deficiency positive patients in a study by Hashmi et al ${ }^{11}$. The estimated sample size was calculated and found to be 101 cases. All the parameters; including age at diagnosis, gender, family history and frequency of smoking (smokers/ non-smokers) were recorded from institutional tumor registry section. All those cases that were diagnosed as poorly differentiated adenocarcinoma or either showed tumor infiltrating lymphocytes and/or mucinous component were selected. Patients with inadequate record of diagnosis of CRC and those who did not undergo surgical resections were excluded. The formalinfixed paraffin-embedded tissue sections of tumors with their matched normal tissues were prepared for 101 cases. Ethical approval for this study was obtained from the Institutional review board of the Armed Forces Institute of Pathology (AFIP) Rawalpindi (Ref: 
FC-HSP 17-2/READ-IRB/18/595). Immunohistochemical staining was performed on representative tissue blocks by using Dako en Vision method using antibodies MLH1, MSH2, PMS2 and MSH6. Results were interpreted and mismatch repair deficiency status of all the patients was determined. The patients were divided into 4 groups; those lacking expression of at least one MMR gene (mismatch repair deficiency status positive), with combined loss of expression, with loss of expression of all four antibodies and those with no loss of expression (mismatch repair deficiency status negative). The data was analyzed using SPSS-20. The quantitative variables including age were presented by calculating mean and standard deviation while qualitative variable including gender and expression of MSI markers were presented by calculating frequency and percentages. Post stratification, we applied chi-square test and $p$-value $\leq 0.05$ was taken as significant.

\section{RESULTS}

In this study, out of 101 patients with CRC, 71 $(70.3 \%)$ were male and $30(29.7 \%)$ female. Themean age was calculated and found to be $54 \pm 15.9$ years (fig-1).

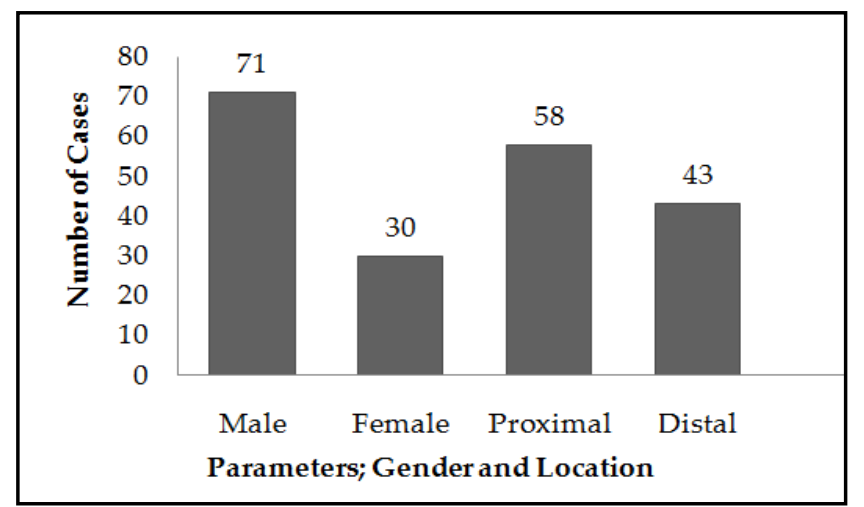

Figure-1: Represent the parameter of gender and location.
Amongst the 101 patients, the loss of IHC staining for MMR proteins was noted in 19 patients (18.8\%). The combined loss of all four antibodies was seen in one patient out of 101 cases (fig-2), loss of MLH1 and PMS2 in 7 patients, MSH2 and MSH6 in 5 cases and MLH1 only in 6 patients. However,no loss of IHC staining for MMR proteins wasdetected in 82 cases. These results were tabulated and presented as shown in the table-I. According to the statistical analysis the $p$-value of each variable; smoking ( $p$-value 1.39), gender ( $p$-value 0.284 ) and age ( $p$-value 1.105) was found to be $>0.05$ hence no significant evidence of association between mismatch repair deficiency status and variables was found (tableII).

Fig-1 representation of parameters; gender and location of tumor for corresponding number of cases under investigation with (mean age 54 years \pm 15.9 ). Out of 101 cases, 65 were found out to be smokers and 36 nonsmokers.

Fig-2(A-J) represents Immunohistochemical staining performed on representative tissue blocks by using Dakoen Vision method using antibodies MLH1 (C and D), PMS2 (E and F), MSH2 (G and H) and MSH6 (I and J) $(\mathrm{A}-\mathrm{I}=100 \mathrm{X}$ magnification, $\mathrm{B}-\mathrm{J}=400 \mathrm{X}$ magnification) and its expression in the colorectal tumor $(\mathrm{A} \& \mathrm{~B})$. The combined loss of all four antibodies seen in one patient out of 101 cases.

\section{DISCUSSION}

The frequency of mismatch repair deficiency in 101 cases of Colorectal carcinoma (CRC) was observed in our study. The four essential parameters (variables) including; age, gender, location of tumor and smoking were taken under consideration as part of study. However, using the online software, SPSS the mean age of the 101 patients was calculated as 54 years \pm 15 .9. In

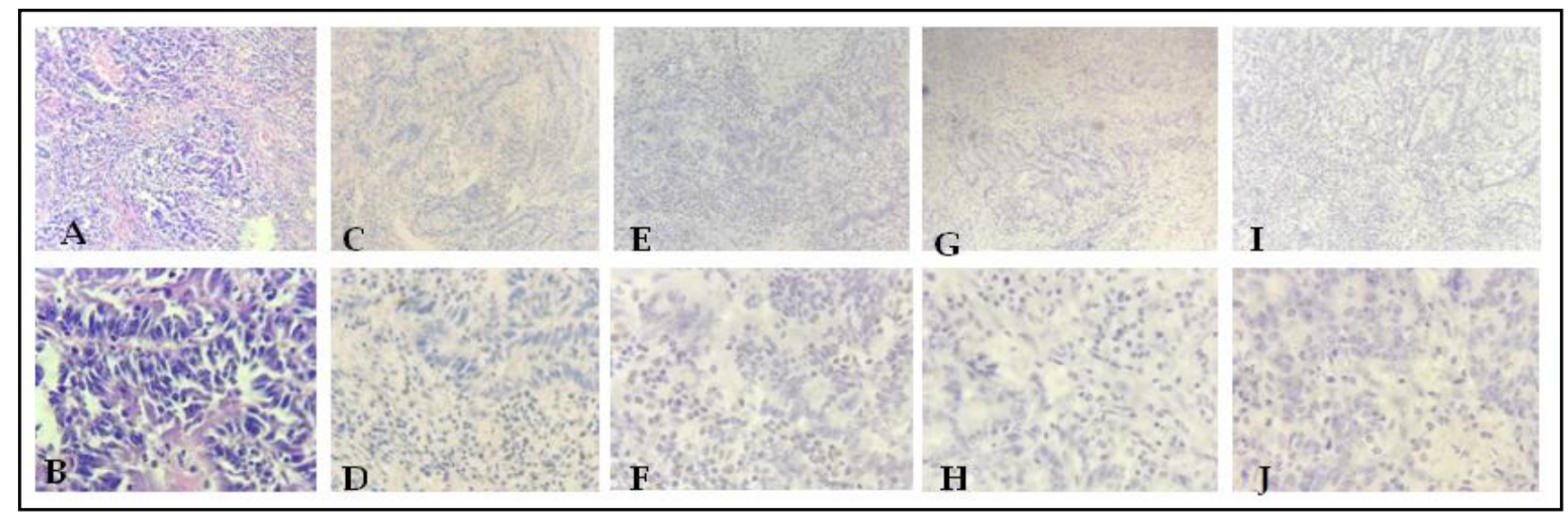

Figure-II: Immunohistochemical expression of MSI markers in colorectal carcinoma. 
this study, the frequency of mismatch repair deficiency was determined among patients of Colorectal carcinoma which was found to be $18.8 \%$ (19 cases out of 101) as shown in table-I. The loss of expression of all

Table-I: Frequency of loss of IHC staining of MLH1, PMS2, MSH2 and MSH6 observed in 19 cases $(n=19)$ out of 101.

\begin{tabular}{l|c}
\hline Patterns & Number of Cases \\
\hline MLH1+PMS2+MSH2+MSH6 & 1 \\
\hline MLH1+PMS2 & 7 \\
\hline MSH2 and MSH6 & 5 \\
\hline MLH1only & 6 \\
No loss of IHC staining & 82 \\
\hline
\end{tabular}

four antibodies was found in $1 \%$ of the cases $(n=1$ out of 101 cases), which is lower than the frequency found in a studyconducted by Hashmi et al, that reported thefrequency of loss of expression of all four antibodies as $7 \%(\mathrm{n}=7 \text { out of } 100 \text { cases })^{11}$. On the other hand, combined loss of expression of MLH1/PMS2 was found in $7 \%(\mathrm{n}=7$ out of 101 cases) which is lower than the frequency found by Hashmi et al, as loss of expression in $16 \%$ ( $n=16$ out of 100 cases) ${ }^{11}$. The loss of MSH2/ MSH6 and isolated loss of MLH1 is observed in only $5 \%(n=5$ out of 101 cases) and $6 \%$ ( $n=6$ out of 101 cases) respectively. This result was comparable with the prior study conducted by Hashmi et al, reporting the loss of MSH2/MSH6 in $6 \%$ ( $\mathrm{n}=6$ out of 100 cases) and isolated loss of MLH1 in 5 cases ( $n=5$ out of 100 cases) ${ }^{11}$. In two separate studies conducted by Gafa et al, and Vilar et al, the frequency of mismatch repair deficiency was found to be as nearly $15 \%$ being slightly lower thanthe result of our study as mentioned above ${ }^{12,13}$. As shown in table-II, the above study comparison is summarized cancer had increased frequency of mismatched repair as compared to left-sided ${ }^{14}$. In general, large number of tumor-infiltrating cytotoxic lymphocytes was found to be an associating factor between tumors with mismatch repair deficiency possessing longer survival as observed in one study ${ }^{15}$. In general, evidence suggested, the incidence rates of CRC are maximum in Europe, northern America, Australia and New Zealand as compared to South-central Asia and Africa ${ }^{17}$. However, the economically transitioning countries also have increased incidence and mortality rates ${ }^{16}$. In Pakistan, the estimated incidence of CRC is $3.6 \% 17$.

While few prior studies found association between mismatch repair deficiency and variables, this results did not lead to any such conclusion. One of such few studies was conducted by Slattery et al, where strong association of smoking and mismatch repair deficiency positive colon cancer was observed whereas no significant association of smoking with mismatch repair deficiency status was found in this results ${ }^{19}$. Another group of study conducted by Slattery et al, Yang et al, and Samowitz et al, reported the association of smoking with mismatch repair deficiency in sporadic colon cancer. This cancer showed the V600E BRAF mutations and widespread methylation of CIMP (CpG island methylator phenotype $)^{19-21}$. The results were then investigated by the study conducted by Samowitz et al in 1315 cases of colon cancer and concluded that irrespective of the mismatch repair deficiency status, the cigarette smoking is associated with the colon cancer due to V600E BRAF mutations and/or

Table-II: Summary of prior study comparisons with current findings in contrast with; frequency of mismatch repair deficiency, loss of expression of all four antibodies, combined as well as combined and isolated antibody expression.

\begin{tabular}{|c|c|c|c|c|c|}
\hline Author & Year & Frequency of MSI & $\begin{array}{l}\text { Loss of Antibody } \\
\text { Expression }\end{array}$ & $\begin{array}{l}\text { Combined Loss of } \\
\text { Antibody Expression }\end{array}$ & $\begin{array}{l}\text { Combined and Isolated loss } \\
\text { of Antibody Expression }\end{array}$ \\
\hline Vilar et al & 2010 & $15 \%$ & - & - & \\
\hline Gafa et al & 2010 & $15 \%$ & - & - & \\
\hline $\begin{array}{l}\text { Hashmi } \\
\text { et al }\end{array}$ & 2017 & - & $\begin{array}{c}\text { MLH1, PMS2, MSH2 \& } \\
\text { MSH6 } \\
7 \% \text { (7out of } 100 \text { cases) }\end{array}$ & $\begin{array}{c}\text { MLH1/PMS2 } \\
16 \% \\
\text { (16 out of } 100 \text { cases) }\end{array}$ & $\begin{array}{c}\text { MSH2/ MSH6 } \\
6 \% \text { ( } 6 \text { cases) MLH1 } \\
5 \% \text { ( } 5 \text { out of } 100 \text { cases })\end{array}$ \\
\hline AFIP & 2019 & $\begin{array}{c}18 \% \\
\text { (19 out of } 101 \\
\text { cases) }\end{array}$ & $\begin{array}{c}\text { MLH1, PMS2, MSH2 \& } \\
\text { MSH6 } \\
5 \% \text { (1 out of } 101 \text { cases })\end{array}$ & $\begin{array}{c}\text { MLH1/PMS2 } \\
7 \% \\
\text { (7 out of } 101 \text { cases) }\end{array}$ & $\begin{array}{c}\text { MSH2/ MSH6 } \\
5 \% \text { ( } 5 \text { out of } 101 \text { cases) } \\
\text { MLH1 } \\
6 \% \text { (6 out of } 101 \text { cases) }\end{array}$ \\
\hline
\end{tabular}

indicating; frequency of mismatch repair deficiency, loss of expression of antibodies in varied patterns including; all four antibodies, combined and combined as well as isolated.

However, a comparison was drawn in the study conducted by Shen et al, stating that right-sided colon
CIMP methylation ${ }^{19}$. In this study they also reported no association with gender whereas, study conducted by Zisman et al, reported that CRC is associated with younger age group and male predominance ${ }^{19,22}$.

An enhanced responsiveness to adjuvant chemotherapy by CRC with mismatch repair deficiency was 
observed in a study conducted by Elsaleh et al23. This responsiveness was considered with an overall significantly better survival than tumors without mismatch repair deficiency and similar results by Lawes et al, in another study ${ }^{24}$.

\section{CONCLUSION}

In our population the frequency of mismatch repair deficiency in CRC patients was found to be $18.8 \%$ that can be used as a platform to perform genetic testing for monitoring the therapeutic response and to predict the overall survival rate in patients with CRC.

\section{CONFLICT OF INTEREST}

This study has no conflict of interest to be declared by any author.

\section{REFERENCES}

1. Siegel RL, Miller KD, Fedewa SA, Ahnen DJ, Meester RG, Barzi A, et al. Colorectal cancer statistics, 2017. CA: A Cancer J Clin 2017; 67(3): 177-93.

2. Baena R, Salinas P. Diet and colorectal cancer. Maturit 2015; 80(3): 258-64.

3. Yashiro M. Molecular alterations of colorectal cancer with inflammatory bowel disease. Digest Dis Sci 2015; 60(8): 2251-63.

4. Hong SN. Genetic and epigenetic alterations of colorectal cancer. Intest Res 2018; 16(3): 327-30.

5. Sekine S, Mori T, Ogawa R, Tanaka M, Yoshida H, Taniguchi H, et all. Mismatch repair deficiency commonly precedes adenoma formation in Lynch Syndrome-Associated colorectal tumorigenesis. Modern Pathol 2017; 30(8): 1144-51.

6. Gatalica Z, Vranic S, Xiu J, Swensen J, Reddy S. High microsatellite instability (MSI-H) colorectal carcinoma: a brief review of predictive biomarkers in the era of personalized medicine. Familial Cancer 2016; 15(3): 405-12.

7. Diaz LA, Marabelle A, Delord JP, Shapira-Frommer R, Geva R, Peled N, et al. Pembrolizumab therapy for microsatellite instability high (MSI-H) colorectal cancer (CRC) and non-CRC. J Clinical Oncol 2017: 35(15): 3071-71.

8. Lynch HT, Snyder CL, Shaw TG, Heinen CD, Hitchins MP. Milestones of Lynch syndrome: 1895-2015. Natur Rev Can 2015; 15(3): 181-94.

9. Sinicrope FA, Shi Q, Smyrk TC, Thibodeau SN, Dienstmann R, Guinney J, et al. Molecular markers identify subtypes of stage III colon cancer associated with patient outcomes. Gastroenterol 2015; 148(1): 88-99.

10. Lindor NM, Burgart LJ, Leontovich O, Goldberg RM, Cunningham JM, Sargent DJ, et al. Immunohistochemistry versus microsatellite instability testing in phenotyping colorectal tumors. J Clinical Oncol 2002; 20(4): 1043-48.
11. Hashmi AA, Ali R, Hussain ZF, Faridi N, Khan EY, Bakar SM, et al. Mismatch repair deficiency screening in colorectal carcinoma by a four-antibody immunohistochemical panel in Pakistani population and its correlation with histopathological parameters. World J Surg Oncol 2017; 15(1): 116-20.

12. Gafà R, Maestri I, Matteuzzi M, Santini A, Ferretti S, Cavazzini L, et al. Sporadic colorectal adenocarcinomas with high-frequency microsatellite instability: Pathobiologic features, hMLH1 and hMSH2 expression, and clinical outcome. Cancer: Interdisciplinary Inter J Am Cancer Soci 2000; 89(10): 2025-37.

13. Vilar E, Gruber SB. Microsatellite instability in colorectal cancerthe stable evidence. Nature Reviews Clinical Oncol 2010; 7(3): 153-58.

14. Shen H, Yang J, Huang Q, Jiang MJ, Tan YN, Fu JF, Zhu LZ, Fang $\mathrm{XF}$, et al. Different treatment strategies and molecular features between right-sided and left-sided colon cancers. World journal of gastroenterology: WJG 2015; 21(21): 6470-74.

15. Deschoolmeester V, Baay M, Van Marck E, Weyler J, Vermeulen P, Lardon F, et al.. Tumor infiltrating lymphocytes: an intriguing player in the survival of colorectal cancer patients. BMC immunol 2010; 11(1): 19-23.

16. Harris RE. Epidemiology of chronic disease: global perspectives. J Bart Learn 2019. [Internet] Available from: https://www. jblearning. com /catalog/productdetails/9781284-151015.

17. Liu Z, Zhang Y, Niu Y, Li K, Liu X, Chen H, et al. A systematic review and meta-analysis of diagnostic and prognostic serum biomarkers of colorectal cancer. PloS One 2014; 9(8): e103910.

18. Sarwar MR, Saqib A. Cancer prevalence, incidence and mortality rates in Pakistan in 2012. Cogent Med 2017; 4(1): 1288773-78.

19. Samowitz WS, Albertsen H, Herrick J, Levin TR, Sweeney C, Murtaugh MA, et al. Evaluation of a large, population-based sample supports a $\mathrm{CpG}$ island methylator phenotype in colon cancer. Gastroenterol 2005; 129(3): 837-45.

20. Yang P, Cunningham JM, Halling KC, Lesnick TG, Burgart LJ, Wiegert EM, et al. Higher risk of mismatch repair-deficient colorectal cancer in a1-antitrypsin deficiency carriers and cigarette smokers. Molecul Genet Metabol 2000; 71(4): 639-45.

21. Samowitz WS, Albertsen H, Sweeney C, Herrick J, Caan BJ, Anderson $\mathrm{KE}$, et al. Association of smoking, CpG island methylator phenotype, and V600E BRAF mutations in colon cancer. J National Cancer Instit 2006; 98(23): 1731-38

22. Zisman AL, Nickolov A, Brand RE, Gorchow A, Roy HK. Associations between the age at diagnosis and location of colorectal cancer and the use of alcohol and tobacco: implications for screening. Arch Inter Med 2006; 166(6): 629-34.

23. Elsaleh H, Joseph D, Grieu F, Zeps N, Spry N, Iacopetta B. Association of tumour site and sex with survival benefit from adjuvant chemotherapy in colorectal cancer. Lancet 2000; 355(9217): 1745-50.

24. Lawes DA, Sen Gupta S, Boulos PB. The clinical importance and prognostic implications of microsatellite instability in sporadic cancer. Europ J Surg Oncol 2003; 29(3): 201-12. 